\title{
Fuzzy Real Options in Brownfield Redevelopment Evaluation
}

\author{
Qian Wang, ${ }^{1}$ Keith W. Hipel, ${ }^{1}$ and D. Marc Kilgour ${ }^{2}$ \\ ${ }^{1}$ Department of Systems Design Engineering, University of Waterloo, Waterloo, ON, Canada N2L 3G1 \\ ${ }^{2}$ Department of Mathematics, Wilfrid Laurier University, Waterloo, ON, Canada N2L 3C5
}

Correspondence should be addressed to Qian Wang, q4wang@uwaterloo.ca

Received 22 December 2008; Accepted 22 March 2009

Recommended by Lean Yu

Real options modeling, which extends the ability of option pricing models to evaluate real assets, can be used to evaluate risky projects because of its capacity to handle uncertainties. This research utilizes possibility theory to represent private risks of a project, which are not reflected in the market and hence are not fully evaluated by standard option pricing models. Using a transformation method, these private risks can be represented as fuzzy variables and then priced with a fuzzy real options model. This principle is demonstrated by valuing a brownfield redevelopment project using a prototype decision support system based on fuzzy real options. Because they generalize the original model and enable it to deal with additional uncertainties, fuzzy real options are entirely suitable for the evaluation of such projects.

Copyright (C) 2009 Qian Wang et al. This is an open access article distributed under the Creative Commons Attribution License, which permits unrestricted use, distribution, and reproduction in any medium, provided the original work is properly cited.

\section{Introduction}

An option is the right, but not the obligation, to buy or sell a certain security at a specified price at some time in the future [1]. The option pricing model developed by Black and Scholes [2] and Merton [3] is widely used to price financial derivatives. Because option pricing quantifies the values of uncertainties, this technique has migrated to broader usage, such as strategy selection [1], risky project valuation [4,5], and policy assessment [6]. The idea of employing an option pricing model to value real assets or investments with uncertainties is usually called the real options approach or real options modeling [1, 7]. In real options, risky projects are modeled as a portfolio of options that can be valued using option pricing equations [4].

As options become "real" rather than financial, the underlying uncertainties become harder to deal with. Some risks associated with real options are not priced in the market, violating a basic assumption of option pricing. Hence, volatilities in real options usually cannot be accurately estimated. 
The methods proposed to overcome the problem of private risk include utility theory $[1,7]$, the Integrated Value Process [4], Monte-Carlo simulation [8, 9], and unique and private risks [10]. This paper uses fuzzy real options, developed by Carlsson and Fuller [11], to represent private risk. Representing private risks by fuzzy variables leaves room for information other than market prices, such as expert experience and subjective estimation, to be taken into account. In addition, the model of Carlsson and Fuller can be generalized to allow parameters other than present value and exercise price [11] to be fuzzy variables, utilizing the transformation method of Hanss [12]. The added flexibility that allows the fuzzy real options model to tackle private risks issue also makes it more suitable for risky project evaluations.

We build a fuzzy real options model for brownfield evaluation by extending Lentz and Tse's [13], and develop a prototype decision support system for brownfield redevelopment evaluation to demonstrate the effectiveness of the fuzzy real options approach.

In this paper, option pricing models are introduced first and then used to value real assets as real options. The main issue of real options, private risks, will be addressed systematically. After a summary and comparison of methods to evaluate private risks, this research will focus on fuzzy real options. After a theoretical introduction, brownfield redevelopment, a typical risky project, is discussed briefly. Then a DSS for brownfield valuation based on fuzzy real options is designed and implemented as a prototype.

\section{Fuzzy Real Options and Private Risks}

\subsection{Real Options}

Black, Scholes, and Merton proposed their frameworks for pricing basic call and put options $[2,3]$ in 1973, establishing the theoretical foundation for pricing all options. Because option pricing models acknowledge the value of uncertainty explicitly, they came to be used to evaluate uncertain real assets, called real options. For instance, the managerial flexibility to terminate a project if it proves unprofitable was recognized as a kind of American put option, with sunk cost as the exercise price. Hence, the value of this risky project would be the sum of its initial cash flows and the value of its derivative American put option [8].

As suggested by the above example, the value of a risky project includes not only its present value, but also the portfolio of options associated with it, reflecting the values of uncertainties and associated managerial flexibilities. The following options may exist in different kinds of projects and situations and can be evaluated using option formulas developed for the financial market [1, 5, 7-9].

(i) The option to defer. The option of waiting for the best time to start a project can be valued as an American call option or a Bermuda call option.

(ii) The option to expand. The option of expanding the scale of the project can be valued as an American call option or a barrier option.

(iii) The option to contract. The option of shrinking the scale of the project can be valued as an American put option.

(iv) The option to abandon. The ability to quit the project can be valued as an American put option or a European put option. 
(v) The option of staging. The ability to divide projects into several serial stages, with the option of abandoning the project at the end of each stage ("option on option"), can be valued as a compound option, also called the learning option in some articles.

(vi) The option to switch. The flexibility to change the project to another use can be valued as a switch option.

The output of option pricing models usually includes valuations, critical values, and strategy spaces to help a DM to make decisions [1]. This information includes

(i) Valuations. The most important output, and the main reason for using a real options model, is the value of the risky project.

(ii) Critical values. Threshold distinguishing the best strategy is usually defined in terms of parameters. For example, some critical values determine whether it is optimal to undertake the project. Critical values play a similar role to Net Present Value (NPV) zero.

(iii) Strategy space. The critical values divide the multidimensional strategy space into regions, corresponding to which option is best to implement. Often, this output is optional.

\subsection{Private Risks}

Unlike the uncertainties reflected in stock or bond prices or exchange rates, market data gives very little information about uncertainties in real options. Moreover, inappropriate consideration of uncertainties may make the real options model invalid, an important issue because of the basic assumptions of option pricing models $[4,14]$.

(i) Complete market. All risks can be hedged by a portfolio of options [15]. In other words, all risks have been reflected in the market price and can be replicated as options. In some literature, this is also called the Market Asset Disclaimer (MAD) approach [5].

(ii) Arbitrage-free market. There is no profit opportunity unless a player in the market is willing to take some risk [4]. In other words, there is no risk-free way of making money.

(iii) Frictionless market. There are no barriers to trading, borrowing, or shorting contracts, and no transaction costs for doing so. Furthermore, underlying assets are infinitely divisible [14].

These assumptions are generally realistic in the financial market, but may not be the case for real options, in part because of the many distinct sources of uncertainty. But more importantly, many uncertainties cannot be matched by any basked of market good, violating the complete market assumption [14]. In fact, it is unusual for project-specific uncertainties to be replicated as a market portfolio. The options modeling process must be customized to make the valuation framework flexible enough to fit real options.

In summary, private risk refers to risks that cannot be valued in the market [1], a simple but difficult issue in applying any real options model. Private risk challenges the complete market assumption, making the output values unreliable. Volatility $(\sigma)$, which reflects uncertainties, cannot be estimated objectively. 


\subsection{Fuzzy Real Options}

Projects usually have private risks, which usually cannot be estimated without expert knowledge. Using soft-computing techniques, experts can use their experience to make subjective predictions of private risk. These predictions can be improved using machine learning algorithms. Accumulating additional cases adds to expert experience, so that learning improves the accuracy of private risk estimation.

Among soft-computing techniques, fuzzy systems theory is especially suitable for representation of expert knowledge. Here, fuzzy real options are intended to deal with private risks that are hard to estimate objectively. The plan is to base fuzzy real options on possibility theory $[11,16-18]$.

The fuzzy approach cannot only model preferences [17], but also take into account subjective uncertainty [11]. In addition, it often requires less data, making it easier to use and quicker to produce satisfactory outputs.

Carlsson and Fuller assume that the present value and exercise price in the option formula are fuzzy variables with trapezoidal fuzzy membership functions. Because inputs include fuzzy numbers, the value of a fuzzy real options is a fuzzy number as well. A final crisp Real Option Value (ROV) can be calculated as the expected value of the fuzzy ROV [11]. Using $\alpha$-cuts $\left(a^{(\alpha)}\right.$ and $b^{(\alpha)}$ denote, respectively, the minimum and maximum values at the $\alpha$-level of membership of a fuzzy variable), the possibilistic mean of the fuzzy variable (denoted $A$ ) and the variance was calculated by [11] to be (2.1) and (2.2), respectively.

$$
\begin{aligned}
E(A) & =\int_{0}^{1} \alpha\left(a^{(\alpha)}+b^{(\alpha)}\right) d \alpha \\
\sigma^{2}(A) & =\frac{1}{2} \int_{0}^{1} \alpha\left(b^{(\alpha)}-a^{(\alpha)}\right)^{2} d \alpha .
\end{aligned}
$$

The concise and effective fuzzy real options approach proposed by Carlsson and Fuller is widely applicable; see [19-21]. But this specific model restrict fuzzy variables to the exercise price and current cash flow. Here, that restriction is avoided by employing fuzzy arithmetic and the transformation method, which is introduced in the following section.

\subsection{Fuzzy Arithmetics and the Transformation Method}

While fuzzy logics and inferencing systems are well-established, fuzzy arithmetic lags behind. Fuzzy arithmetic is restricted to simple operators [22, 23]. In applications, fuzzy arithmetic is usually limited to several predefined membership functions in MATLAB and Mathematica. This is mainly because the final result may be different depending on the procedure for implementing standard fuzzy arithmetic [12].

Hanss established the transformation method, thereby solving the multiple outputs problem and making generalized fuzzy arithmetic possible [24]. In the transformation method, a fuzzy function is defined as in Definition 2.1).

Definition 2.1. A fuzzy function with fuzzy output $\tilde{q}, n$ fuzzy inputs $\tilde{p}_{j}$, and $k$ normal inputs $x_{k}$, can be expressed as

$$
\tilde{q}=F\left(x_{1}, x_{2}, \ldots, x_{k} ; \widetilde{p_{1}}, \widetilde{p_{2}}, \ldots, \widetilde{p_{n}}\right)
$$


The idea underlying the transformation method has three important points: decompose fuzzy numbers into discrete form, use an $\alpha$-cut for calculation purposes as a traditional function, and search the coordinates of the points in the hypersurfaces of the cube. The algorithm of the transformation method is given next [12]:

\subsubsection{Decomposition of the Input Fuzzy Numbers}

Similar to (2.1), $d \alpha$ is discretized into a large number of $m$ intervals of length $\Delta \alpha=1 / m$. Each fuzzy input $\tilde{p}_{i}$ is decomposite into a series of crisp values at different $\alpha$-cut levels $\mu_{j}$, where $\mu_{j}=(j / m)(j=0,1, \ldots, m)$

$$
P_{i}=\left\{X_{i}^{\left(\mu_{0}\right)}, X_{i}^{\left(\mu_{1}\right)}, \ldots, X_{i}^{\left(\mu_{j}\right)}, \ldots, X_{i}^{\left(\mu_{m}\right)}\right\}, \quad i=1,2, \ldots, n,
$$

where every element $X_{i}^{(j)}$ is define as

$$
X_{i}^{\left(\mu_{j}\right)}=\left[a_{i}^{\left(\mu_{j}\right)}, b_{i}^{\left(\mu_{j}\right)}\right]
$$

where $a_{i}^{\left(\mu_{j}\right)}$ and $b_{i}^{\left(\mu_{j}\right)}$ denote the minimum and maximum values at the $\mu_{j}$-level of a given fuzzy variable, respectively, as previous.

\subsubsection{Transformation of the Input Intervals}

The intervals $X_{i}^{(j)}, i=1,2, \ldots, n$ of each level of membership $\mu_{j}, j=0,1,2, \ldots, m$, are transformed into arrays $\widehat{X_{i}^{j}}$ of the form with the number of $2^{i-1}$ pairs $\left(\alpha_{i}^{(j)}, \beta_{i}^{(j)}\right)$,

$$
\widehat{X}_{i}^{j}=\left(\left(\alpha_{i}^{(j)}, \beta_{i}^{(j)}\right),\left(\alpha_{i}^{(j)}, \beta_{i}^{(j)}\right), \ldots,\left(\alpha_{i}^{(j)}, \beta_{i}^{(j)}\right)\right)
$$

with $2^{n-i}$ elements in each set of

$$
\alpha_{i}^{(j)}=\left(a_{i}^{(j)}, \ldots, a_{i}^{(j)}\right), \quad \beta_{i}^{j}=\left(b_{i}^{j}, \ldots, b_{i}^{j}\right)
$$

The above formula fits the case of the reduced transformation method when the fuzzy function is monotonic or has only one fuzzy input. The general transformation method is similar to these formulae [12]. The main difference is that more points are tested.

Denotion of $\alpha_{i}^{(j)}$ and $\beta_{i}^{(j)}$ as pairs of $\alpha$-cut values allows repetitive elements. The order of the elements is critical. The ultimate goal is that the $2^{i-1}$ of the $i$ th element forms endpoints on the hypersurfaces. As illustrated in Figure 1, in the case of 3 fuzzy inputs shown as 3dimensional space, the above definition means every $X_{i}^{(j)}$ has $2^{n-i} * 2^{i-1}=2^{n}=2^{3}=8$ elements, which are located on the endpoints of the cubicle. 


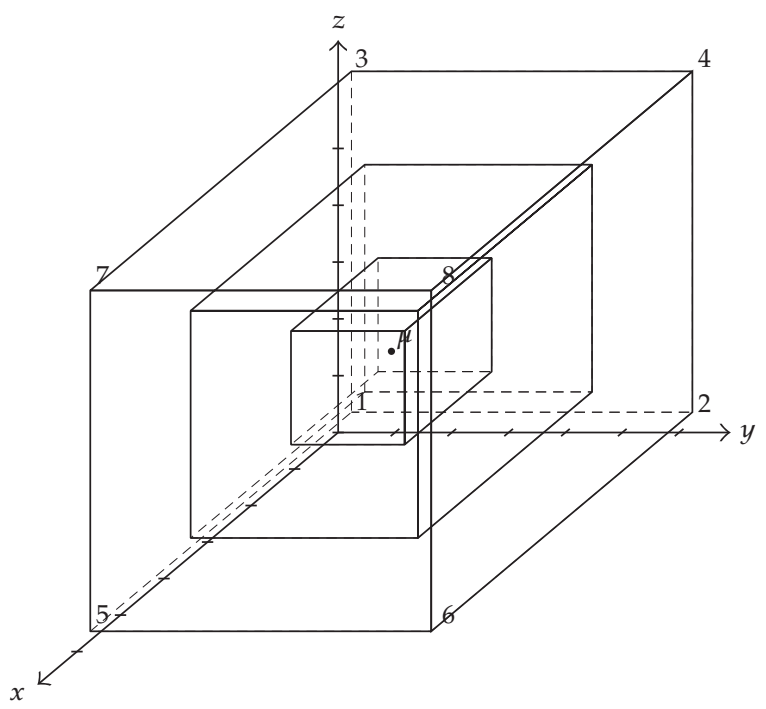

Figure 1: Fuzzy transformation diagram [12].

\subsubsection{Evaluation of the Model}

The function $F$ is evaluated separately at each of the columns in the arrays using the classical arithmetic for crisp numbers. In other words, if the output $\tilde{q}$ can be decomposed to the arrays $\widehat{Z}^{(j)}(j=0,1,2, \ldots, m)$ using the algorithms mentioned above, the $k$ th element can be obtained using the formula as

$$
{ }^{k} \widehat{z}^{(j)}=F\left({ }^{k} \widehat{x}_{1}^{(j)},{ }^{k} \widehat{x}_{2}^{(j)}, \ldots,{ }^{k} \widehat{x}_{n}^{(j)} ; y_{1}, y_{2}, \ldots, y_{l}\right)
$$

where ${ }^{k} \widehat{x}_{i}^{(j)}$ is the $k$ th element of the array $\widehat{X}_{i}^{(j)}$ and $y_{i}(i=1,2, \ldots, k)$ are the other crisp inputs of the function.

\subsubsection{Retransformation of the Output Array}

Now the decomposition of the fuzzy output $\tilde{q}$ becomes the set $Q=\left\{Z^{(0)}, Z^{(1)}, Z^{(2)}, \ldots, Z^{(m)}\right\}$. Each element of this set should be the $\alpha$-cut value at each level just like (2.5). Each value is obtained by retransforming the arrays $\widehat{Z}^{(j)}$ in a recursive manner using the following formula:

$$
\begin{aligned}
a^{(j)} & =\min \left(a^{(j+1)}, k_{\widehat{z}}(j)\right), \quad j=0,1, \ldots, m-1, \\
b^{(j)} & =\max \left(b^{(j+1)}, k_{\widehat{z}^{(j)}}\right), \quad j=0,1, \ldots, m-1, \\
a^{(m)} & =\min \left({ }^{k} \widehat{z}^{(m)}\right), \quad b^{(m)}=\max \left({ }^{k} \widehat{z}^{(m)}\right) .
\end{aligned}
$$




\subsubsection{Recomposition of the Output Intervals}

Recompositing the inverals $Z^{(j)}, j=0,1,2, \ldots, m$ of the set $Q$ based on their membership level $\mu_{j}$, we can get the final fuzzy output $\tilde{q}$.

The transformation method is an ideal solution for implementing generalized arithmetic operations. Hence, it is employed in this paper to integrate the subjective uncertainties into the real options model. This algorithm is one of the key components in building the decision support system for the project evaluation of brownfield redevelopment using the fuzzy real options.

\section{Brownfield Redevelopment}

\subsection{Uncertainties in Brownfield Redevelopment}

A brownfield is an abandoned or underutilized property that is contaminated, or suspected to be contaminated, usually due to previous industrial usage [25]. Brownfields are common in cities transitioning from an industrial to a service-oriented economy, or when industrial enterprises have been relocated elsewhere or restructured themselves [26]. Brownfields are associated with an unsustainable development pattern, as they often arise when greenfields are developed while brownfields are abandoned.

Hence, brownfield redevelopment is helpful in enhancing regional sustainability. For example, municipal governments in Canada and elsewhere are encouraging brownfield redevelopment as part of a regional sustainable development plan. If brownfields were successfully redeveloped, local economic transitions would be more fluid; current infrastructure would be reused, and local public health would be more secure.

Brownfield redevelopment is a typical system-of-systems (SoSs) problem, as it involves various systems with complex interactions as illustrated in Figure 2. Brownfield redevelopment has the characteristics of an SoS; it possesses high uncertainty, nonlinear interactions within and among systems and is interdisciplinary in nature [27]. Due to the complex interactions of soil and groundwater systems with societal systems, as well as uncertainties in redevelopment costs, knowledge and technologies, and potentially high liabilities, brownfield redevelopment is difficult to initiate [28]. Uncertainties in brownfield redevelopment can be classified into the following categories.

(i) Uncertainties due to limited knowledge of brownfields. Currently, knowledge and data about brownfields are limited. Identifying appropriate models, characteristics, and parameters can be costly and time-consuming.

(ii) Uncertainties originating from environmental systems. Environmental systems have complex interactions in different systems, especially between groundwater and soil. Complex site-specific characteristics hinder remediation and redevelopment processes because they usually lead to highly uncertain remediation costs [29].

(iii) Uncertainties originating from societal systems. There are various kinds of stakeholders in brownfield redevelopment participating in complex conflicts and interactions, which create high levels of uncertainty in liabilities and cost sharing polices.

Because of the high uncertainties involved in brownfield redevelopment, traditional valuation methods are inoperable. It is very difficult to identify an appropriate discount rate for the Capital Asset Pricing Model (CAPM) [30]. Developers normally require highrisk premiums to compensate for the high uncertainties in brownfield redevelopment 


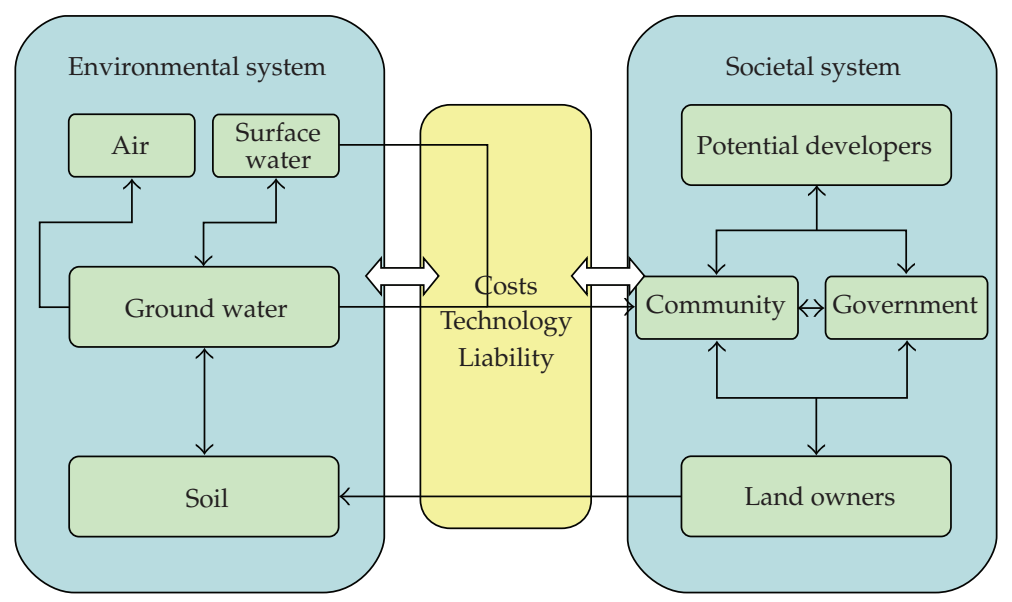

Figure 2: Systems diagram of brownfield redevelopment.

projects. Using Net Present Values (NPVs), developers usually calculated negative values for redevelopment projects and thus were reluctant to undertake them [31].

However, brownfield redevelopment can be profitable and even produces higher investment returns in some cases [31-33]. One explanation of the gap between predicted (conceptual) profit using NPV and the actual investment return is that the NPV method fails to map the value of opportunities created under a high uncertainty environment into project values.

These observations motivate the use of the real options model to evaluate redevelopment projects; it may provide more accurate valuations in the presence of high uncertainties. This research builds a prototype decision support system to implement a fuzzy real options model. The effectivenss of the model is tested using hypothetical data derived from actual brownfield redevelopment projects.

\subsection{Fuzzy Real Options for Brownfield Redevelopment}

Among a couple of available real options models for brownfield redevelopment, model proposed by Lentz and Tse is chosen to be extended with fuzzy variables, which includes an option to remove hazardous materials at the best time and an option to redevelop the brownfield, converting this site into other more profitable usage, at the best opportunity [13]. This model is more generic than others, such as Espinoza and Luccioni [32], in which only one American option is considered and Erzi-Akcelik [33], in which just applied Dixit and Pindyck's model [7]. Hence, an option to defer and option to learn are involved in the evaluation of contaminated properties.

The value of brownfield sites is regarded as two Wiener processes: the cash flow generated from this site without contamination (denoted as $x$ ) and the redevelopment cost for this site (denoted as $R$ ). To make private risks distinct from market ones, both of them are treated as two partially hedged portfolios, cash flow portfolio (denoted as $P$ ) and redevelopment cost (denoted as $K$ ), respectively.

In addition, four coefficient parameters with regard to $x$ and $R$ are involved. The parameters $\varphi_{1}$ and $\phi$ focus on cash flows. As cash flows from all states are being proportional 


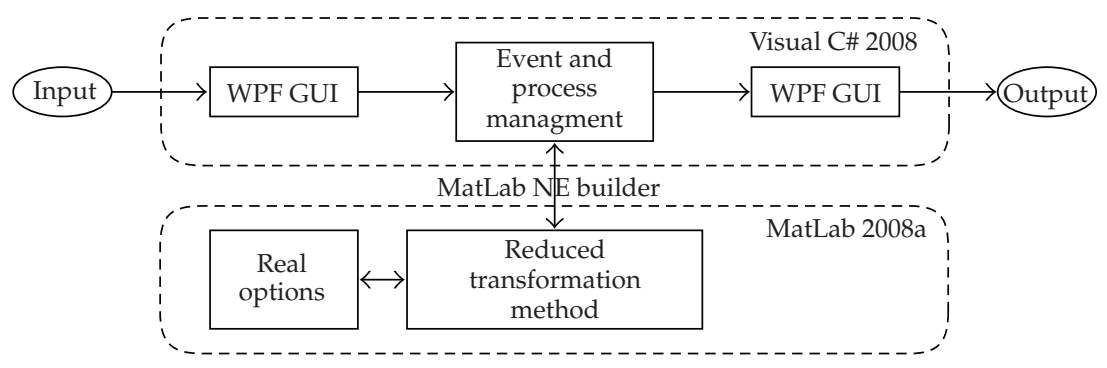

Figure 3: System architecture of the DSS.

to the clean one, the cash flow generated under contamination is $\varphi_{1} x$; cash flow after removal is regarded as resumed to the clean one with $x$; and cash flow after redevelopment is $\phi x$. The coefficients $\alpha_{1}$ and $\alpha_{2}$ denote the removal and restoration costs as $\alpha_{1} R$ and $\alpha_{2} R$, which are assumed to be proportional to the total redevelopment $\operatorname{cost} R$ as well. Therefore, the cleanup cost $C$ equals $\left(\alpha_{1}+\alpha_{2}\right) R$.

Overall, three critical values are involved in deciding three kinds of strategies, which are denoted as $Z^{*}, Y^{*}$, and $W^{*}$ in [13, Formula 14]: do nothing, remove pollutants and redevelop sequentially, or remove and redevelop simultaneously. Values to be compared with these critical values are, respectively, $Z=x / R$, the ratio of the clean cash flow $(x)$ to the redevelopment cost $(R), Y=x / C$, the ratio of the clean cash flow $(x)$ to the cleanup cost $(C)$, and $W=x /\left(1+\alpha_{1}\right) R$, the ratio of the clean cash flow $(x)$ to the combined cost of removal and redevelopment as a joint action. In addition, all supplementary formulae are shown as [13, Formula 12]:

$$
\begin{gathered}
\sigma^{2}=\sigma_{x}^{2}+\sigma_{R}^{2}-2 \sigma_{x R}, \\
\gamma=\omega_{k}-\mu_{R}, \\
\delta=g-\left(\mu_{R}-\mu_{K}+r\right), \\
g=\mu_{x}-\left(\mu_{P}-r\right) \beta_{x}, \\
\beta_{x}=\rho_{x P} \frac{\sigma_{x}}{\sigma_{P}}, \\
\beta_{R}=\rho_{R K} \frac{\sigma_{R}}{\sigma_{K}}, \\
\omega_{K}=r+\left(\mu_{K}-r\right) \beta_{R}, \\
q=0.5\left(\frac{\sigma^{2}-2 \delta}{\sigma^{2}}+\sqrt{\frac{\left(2 \delta-\sigma^{2}\right)^{2}+8 \gamma \sigma^{2}}{\sigma^{4}}}\right) .
\end{gathered}
$$

If the contaminated properties were to be cleaned and redeveloped sequentially, their values can be expressed as [13, Formula 13], depending on the critical value of $Y^{*}$ as [13, Formula 14]. If $Y>Y^{*}$, the removal action should be taken right now. Otherwise, the optimal 
executing time is in [13, Formula 16]. After the cleanup action, redevelopment is better to be conducted when $Z>Z^{*}$ in (3.5):

$$
V 1=\left\{\begin{array}{cc}
\frac{\varphi_{1} x}{r-g}+\left(\frac{(q-1)^{q-1}}{q^{q}}\right)\left(\left(\frac{1-\varphi_{1}}{r-g}\right)^{q}\left(\frac{x}{C}\right)^{q-1}+\left(\frac{\phi-1}{r-g}\right)^{q}\left(\frac{x}{R}\right)^{q-1}\right) x, & \text { if } Y \leq Y^{*} \\
\frac{x}{r-g}+\left(\frac{(q-1)^{q-1}}{q^{q}}\right)\left(\frac{\phi-1}{r-g}\right)^{q}\left(\frac{x}{R}\right)^{q-1} x-C, & \text { if } Y>Y^{*} \\
Y^{*}=\frac{r-g}{1-\varphi_{1}} \frac{q}{q-1} \\
W^{*}=\frac{r-g}{\phi-\varphi_{1}} \frac{q}{q-1} \\
Z^{*}=\frac{r-g}{\phi-1} \frac{q}{q-1}
\end{array}\right.
$$

If the brownfield sites were to be cleaned and redeveloped simultaneously, their values can be expressed in [13, Formula 15], depending on the critical value of $W^{*}$ in (3.3). If $W>$ $W^{*}$, the removal action should be taken right now. Otherwise, the optimal executing time is in (3.5):

$$
\begin{aligned}
& V 2= \begin{cases}\frac{\varphi_{1} x}{r-g}+\left(\frac{\phi-\varphi_{1}}{r-g}\right)^{q}\left(\frac{(q-1)^{q-1}}{q^{q}}\right) \frac{x^{q}}{\left(\alpha_{1} R+R\right)}, & \text { if } W \leq W^{*} ; \\
\frac{\phi x}{r-g}-\left(\alpha_{1} R+R\right), & \text { if } W>W^{*} ;\end{cases} \\
& \tau_{Y}=\frac{\ln Y^{*}-\ln Y}{m_{x}-m_{R}}, \\
& \tau_{W}=\frac{\ln W^{*}-\ln W}{m_{x}-m_{R}}, \\
& \tau_{Z}=\frac{\ln Z^{*}-\ln Z}{m_{x}-m_{R}},
\end{aligned}
$$

for $m_{x}>m_{R}$, where $m_{x}=\mu_{x}-0.5 \sigma_{x}^{2}$ and $m_{R}=\mu_{R}-0.5 \sigma_{R}^{2}$.

The final value of the brownfield site is the maximum of $V 1$ and V2. An optimized redevelopment strategy can also be formed based on where it locates in the decision region, since all critical value can be converted into $x / R$.

\section{Decision Support System Design and Case Study}

\subsection{System Architecture}

The system architecture of the DSS is shown in Figure 3. Experts input parameters via the layer of the Windows Presentation Foundation (WPF) are given in Figure 4. After that, an event and process management module will control the work flow to convert all information 


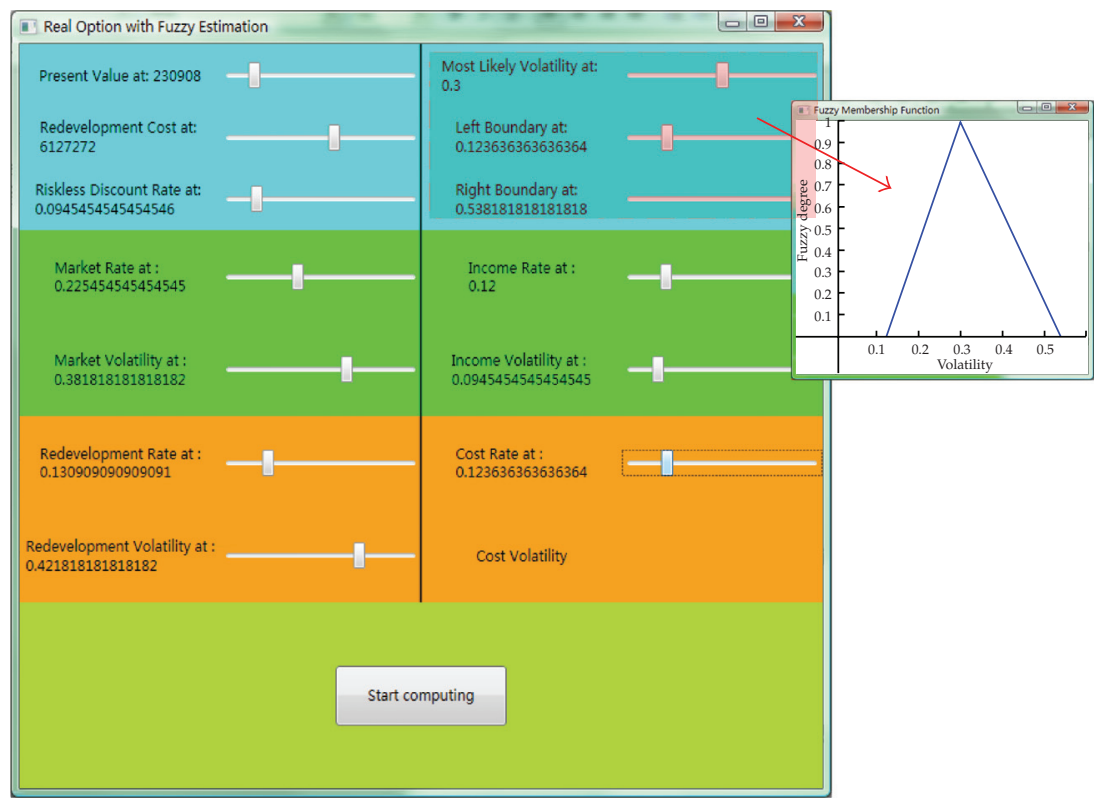

Figure 4: GUI for input of the DSS.

using the format of MatLab and feed them into MatLab for actual computation using the proposed fuzzy real options algorithm. Basically, fuzzy data are first converted (fuzzified and defuzzifed) into the crisp value needed for the real options model. Then, output can be obtained by calling the real options formula. Finally, the last output will be presented graphically via WPF to users.

Although prototype developed in this paper is primitive, the system architecture is quite generic and extendable. This DSS can be gradually expanded in scale and become more complex with more functions. The developed prototype satisfies the goal of a feasibility study on both the algorithm and technical approach in building this DSS.

\subsection{An Illustrative Example}

To demonstrate the fuzzy real options modeling, a brief example using hypothetical values is presented to illustrate an application of the associated DSS. These data mainly come from Lentz and Tse's paper [13], so that the DSS can be tested by comparing with their result. In addition, although inputs data are imaginary, they are modified according to real data in some articles on brownfield redevelopment, such as $[33,34]$ and added with some fuzzy parameters. The input data are shown in Table 1.

In addition to the data used in Table 1, all variables in this model are allowed to be fuzzy ones, in order to incorporate expert knowledge into parameter estimation. Given that the most difficult task in brownfield redevelopment is to estimate uncertainties regarding the redevelopment cost, which belongs to the private risk, the volatility rate of the redevelopment cost, $\sigma_{R}$, is deemed to be a fuzzy variable and studied intensively in this paper.

The volatility of the redevelopment cost is hard to estimate mainly because the dissemination of pollutants underground is highly complex. Soils, rocks, and materials 
Table 1: Input data [13].

\begin{tabular}{lc}
\hline Variable name & Value \\
\hline Current net cash flow of the clean property $(x)$ & $\$ 300000$ \\
Current redevelopment vost $(R)$ & $\$ 5000000$ \\
Riskless interest rate $(r)$ & $5 \%$ \\
\hline Instantaneous return rate of the cash flow $\left(\mu_{x}\right)$ & $10 \%$ \\
Volatility rate of the cash flow $\left(\sigma_{x}\right)$ & $20 \%$ \\
Instantaneous return rate of the portfolio hedging the cash flow $\left(\mu_{P}\right)$ & $15 \%$ \\
Volatility rate of the portfolio hedging the cash flow $\left(\sigma_{P}\right)$ & $20 \%$ \\
\hline Instantaneous return rate of the redevelopment cost $\left(\mu_{R}\right)$ & $7 \%$ \\
Volatility rate of the redevelopment cost $\left(\sigma_{R}\right)$ & $20 \%$ \\
Instantaneous return rate of the portfolio hedging the redevelopment cost $\left(\mu_{K}\right)$ & $15 \%$ \\
Volatility rate of the portfolio hedging the redevelopment cost $\left(\sigma_{K}\right)$ & $16 \%$ \\
\hline Ratio of the contaminated cash flow to the clean one $\left(\varphi_{1}\right)$ & 0.4 \\
Ratio of the restored cash flow to the clean one $\left(\varphi_{2}\right)$ & 1 \\
Ratio of the redeveloped cash flow to the clean one $(\phi)$ & 2 \\
Ratio of the clean-up cost to the redevelopment cost $\left(\alpha_{1}\right)$ & 0.3 \\
Ratio of the restoration cost to the redevelopment cost $\left(\alpha_{2}\right)$ & 0.2 \\
\hline Correlation between the hedging portfolio and underlying cash flow $\left(\rho_{x P}\right)$ & 1 \\
Correlation between the hedging portfolio and underlying cash flow $\left(\rho_{R K}\right)$ & 1 \\
Correlation between the cash flow and the redevelopment cost $\left(\rho_{x R}\right)$ & 0 \\
\hline Note: Parameters, $\varphi_{1}, \varphi_{2}, \phi, \alpha_{1}, \alpha_{2}, \rho_{x P}, \rho_{R K}, \rho_{x R}$, are predefined in the DSS to simplify inputs. And since they are mainly \\
coefficient parameters, there is no need to change them frequently.
\end{tabular}

are distributed ununiformly. Their hydraulic conductivities vary greatly according to the materials, elevation, and seasonal change. For instance, groundwater passes through peat (or cinders) at the velocity of $177 \mathrm{~cm} / \mathrm{d}$, which is hundreds of times the speed in the silt till $(0.49 \mathrm{~cm} / \mathrm{d})$ at the site of the Ralgreen Community in Kitchener, ON, Canada [34]. Moreover, redevelopment cost also depends on the residual rate of pollutants and excavation cost, which are hard to estimate using market data neither.

To overcome this problem, the fuzzy redevelopment volatility is utilized as one with a triangle membership distribution based on parameters of minimum value, maximum value, and most likely value, because project managers and experts usually estimate uncertain parameters using the three-point estimation method [35]. Based on the hydraulic conductivity, volume of contaminated soil, and elevations, we found that the $20 \%$ volatility rate, used in Tse and Lentz's article [13], is roughly realistic. Nonetheless, since there are only two wells drilled for sampling, a relatively large interval should be added. As the result, the fuzzy redevelopment volatility is inputed as $(0.15,0.2,0.25)$.

The main result from the DSS is shown in Figure 5, which includes the value of the brownfield site, a suggestion for a redevelopment strategy, and associated critical values that lead to this suggestion. In this case, the property value is a fuzzy variable with a mean of around 6.3 million and variance of around 1.7 million. Obviously, the private risk of redevelopment volatility has a great effect on the value of brownfield properties. And because the output indicators $\left(Y\right.$ and $W$ ) are less than their corresponding critical values $\left(Y_{*}\right.$ and $\left.W_{*}\right)$, this site is not worth of redeveloping now. This result partially explains why developers are reluctant to undertake this redevelopment task. 


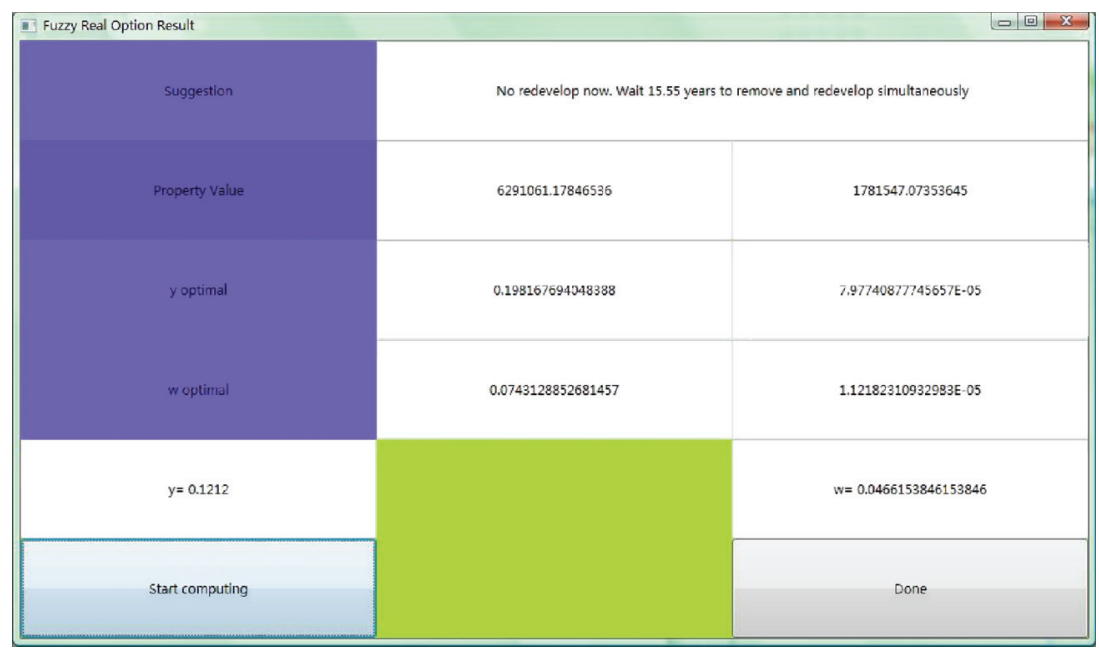

Figure 5: Output for the illustrative example.

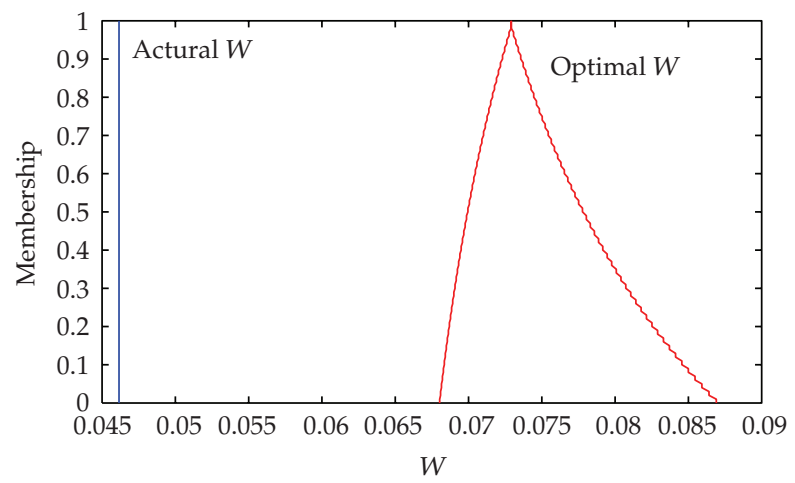

Figure 6: $W$ (the red line in left) and $W^{*}$ with fuzzy boundary (membership function).

Moreover, the critical values are fuzzy outputs as well. The fuzzy boundaries differentiating optimal strategies are illustrated in Figure 6. Also, these critical values can be converted into the ratio of $x / R$ and shown in one figure as different decision regions in the strategy space (Figure 7). Fuzzy areas are calculated based on their fuzzy means and standard deviations. This DSS provides decision makers an intuitive decision suggestion with the aid of the decision region chart.

Finally, the effect of subjective estimation on property value is studied by changing the fuzzy intervals (minimum and maximum values of the fuzzy redevelopment volatility) while holding the most likely value unchanged, also as a kind of sensitivity analysis. Based on the illustrative example, we found that the value of the contaminated property increases as the fuzzy interval enlarges, as shown in Figure 8. This result implies that the subjective estimation of the private risk has an effect on the final evaluation result, although the change is not too much. Furthermore, experts can take advantage of their knowledge to make a slightly higher profit in the brownfield redevelopment projects than others. And the variation of the fuzzy output increases gradually, suggesting that there is no abrupt change and associated critical value in the fuzzy real options model. 


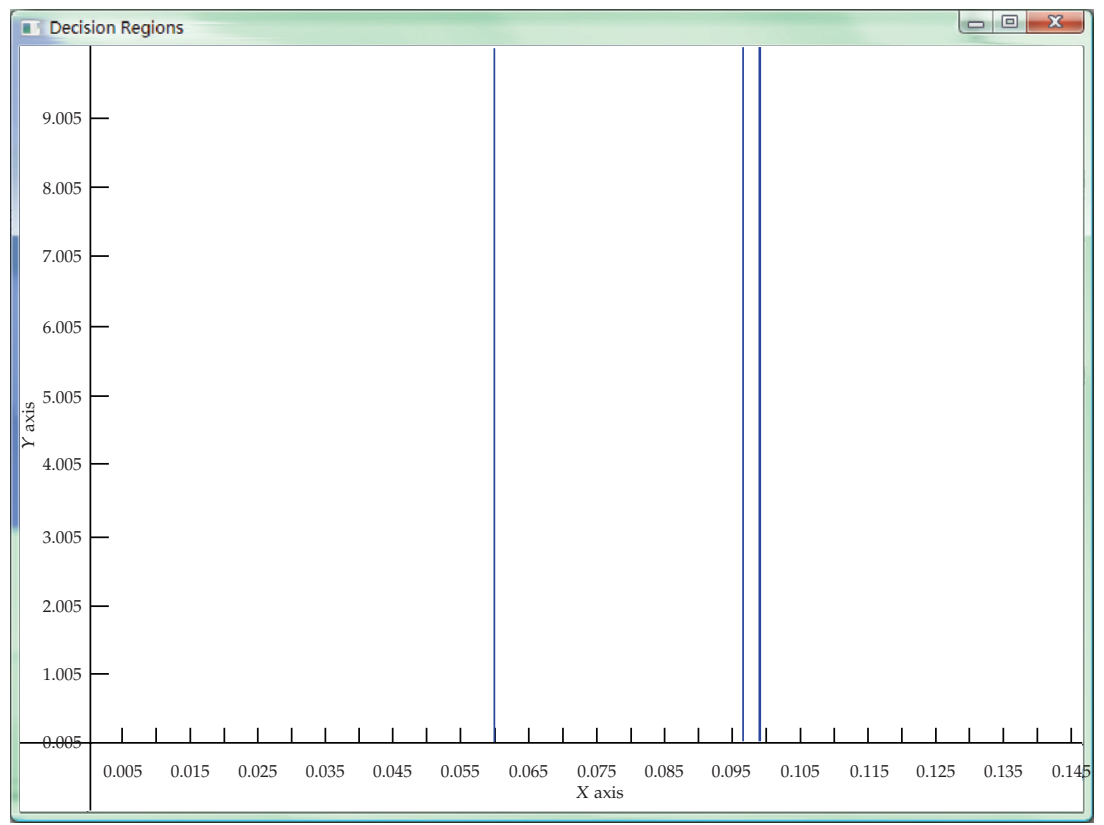

Figure 7: Decision regions divided by $Y^{*}$ and $W^{*}$.

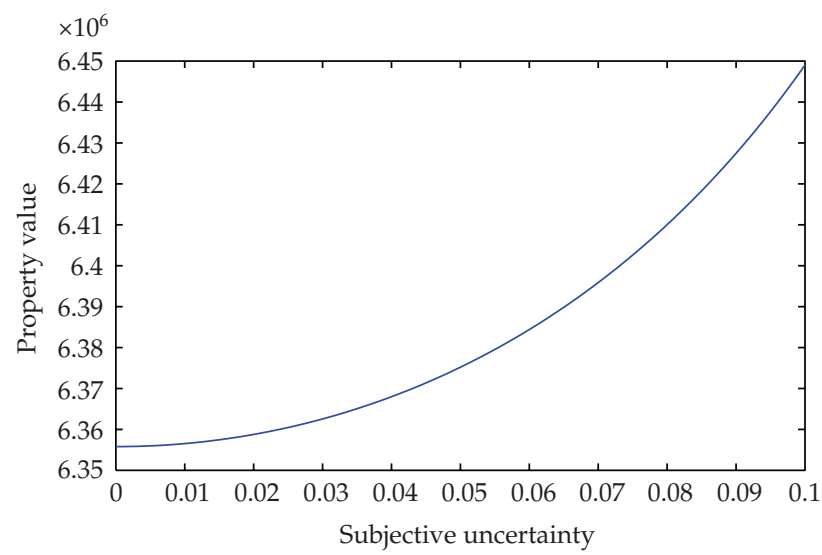

Figure 8: The effect of subjective uncertainty on property value.

\section{Conclusions and Future Work}

This paper employs a fuzzy real options approach to deal with the private risk problem. With help of the transformation method, any parameter in a real option model can be estimated as a fuzzy variable. Based on the results from the illustrative example using the prototype DSS, we found that this approach is effective in dealing with the private risk and generating satisfactory evaluations and useful suggestions. Hence, based on our limited test, the DSS based on the fuzzy real options is a useful tool in risky project evaluations. It potential for application should be further studied. 
In addition, from the result of the illustrative example (Figure 8), we see that possibilities as well as probabilities can affect evaluations of risky projects. For the case of brownfield redevelopment, expertise can be utilized to make the contaminated property more valuable. This effect needs to be further analyzed.

But it should be recognized that the fuzzy real options model in this paper has several limitations, some of which may be removed in future work. Fuzzy arithmetic permits any membership function to be utilized in real options. This flexibility builds a foundation for future application of soft-computing techniques. For instance, the neural network could provide a nonparametric adaptive mechanism for private risk estimation. The DSS will be enhanced if it can be made to behave intelligently and adaptively.

A key feature of the fuzzy real options proposed here the mixture of fuzziness and randomness describing hybrid markets and private risks. But one limitation of our approach is that these two features are not well-integrated. Randomness is represented as a stochastic process, while fuzziness is represented using only fuzzy arithmetic. Incorporating a fuzzy process would clarify the structure, perhaps producing some important new insights.

A unifyied process including both fuzzy and stochastic features could strengthen the idea of fuzzy real options and extend enormous flexibility to soft-computing techniques and statistical models associated with these options. This goal may be achieved with the aid of the chance theory proposed by Liu [36].

Finally, since the fuzzy real options approach helps to improve developers' evaluation on brownfields, game-theoretic approaches could later be employed for negotiation of governmental assistance in the brownfield redevelopment to achieve optimal results.

\section{References}

[1] M. Amram and N. Kulatilaka, Real Options: Managing Strategic Investment in an Uncertain World, Harvard Business School Press, Boston, Mass, USA, 1999.

[2] F. Black and M. Scholes, "The pricing of options and corporate liabilities," Journal of Political Economy, vol. 81, no. 3, pp. 637-659, 1973.

[3] R. C. Merton, "Theory of rational option pricing," Bell Journal of Economics and Management Science, vol. 4, no. 1, pp. 141-183, 1973.

[4] J. E. Smith and R. F. Nau, "Valuing risky projects: option pricing theory and decision analysis," Management Science, vol. 41, no. 5, pp. 795-816, 1995.

[5] M. Schneider, M. Tejeda, G. Dondi, F. Herzog, S. Keel, and H. Geering, "Making real options work for practitioners: a generic model for valuing R\&D projects," RED Management, vol. 38, no. 1, pp. 85-106, 2008.

[6] C. R. Cunningham, "Growth controls, real options, and land development," The Review of Economics and Statistics, vol. 89, no. 2, pp. 343-358, 2007.

[7] A. Dixit and R. Pindyck, Investment under Uncertainty, Princeton University Press, Princeton, NJ, USA, 1994.

[8] J. Mum, Real Options Analysis: Tools and Techniques for Valuing Strategic Investments and Decisions, John Wiley \& Sons, New York, NY, USA, 2002.

[9] T. Copeland and V. Antikarov, Real Options: A Practitioner's Guide, Texere Press, New York, NY, USA, 2003.

[10] M. H. Mattar, Private risk, Ph.D. dissertation, MIT Press, Cambridge, Mass, USA, 2002.

[11] C. Carlsson and R. Fullér, "A fuzzy approach to real option valuation," Fuzzy Sets and Systems, vol. 139, no. 2, pp. 297-312, 2003.

[12] M. Hanss, Applied Fuzzy Arithmetic: An Introduction with Engineering Applications, Springer, Berlin, Germany, 2005.

[13] G. H. Lentz and K. S. M. Tse, "An option pricing approach to the valuation of real estate contaminated with hazardous materials," The Journal of Real Estate Finance and Economics, vol. 10, no. 2, pp. 121-144, 1995. 
[14] M. H. Mattar and C. Y. J. Cheah, "Valuing large engineering projects under uncertainty: private risk effects and real options," Construction Management and Economics, vol. 24, no. 8, pp. 847-860, 2006.

[15] F. P. Ng and H. C. Björnsson, "Using real option and decision analysis to evaluate investments in the architecture, construction and engineering industry," Construction Management and Economics, vol. 22, no. 5, pp. 471-482, 2004.

[16] C. Carlsson and R. Fullér, "On possibilistic mean value and variance of fuzzy numbers," Fuzzy Sets and Systems, vol. 122, no. 2, pp. 315-326, 2001.

[17] D. Dubois and H. Prade, "Possibility theory as a basis for preference propagation in automated reasoning," in Proceedings of the IEEE International Conference on Fuzzy Systems, pp. 821-832, San Diego, Calif, USA, March 1992.

[18] D. Dubois and H. Prade, Possibility Theory: An Approach to Computerized Processing of Uncertainty , Plenum Press, New York, NY, USA, 1988.

[19] J. Wang and W.-L. Hwang, "A fuzzy set approach for R\&D portfolio selection using a real options valuation model ," Omega, vol. 35, no. 3, pp. 247-257, 2007.

[20] D. Allenotor and R. K. Thulasiram, "G-FRoM: grid resources pricing a fuzzy real option model," in Proceedings of the IEEE International Conference on e-Science and Grid Computing, pp. 388-395, Bangalore, India, December 2007.

[21] J.-H. Cheng and C.-Y. Lee, "Product outsourcing under uncertainty: an application of fuzzy real option approach," in Proceedings of the IEEE International Conference on Fuzzy Systems, pp. 1-6, London, UK, July 2007.

[22] M. Ma, M. Friedman, and A. Kandel, "A new fuzzy arithmetic," Fuzzy Sets and Systems, vol. 108, no. 1, pp. 83-90, 1999.

[23] M. Mizumoto and K. Tanaka, "The four operations of arithmetic on fuzzy numbers," Systems Computers and Controls, vol. 7, no. 5, pp. 73-81, 1976.

[24] M. Hanss, "The transformation method for the simulation and analysis of systems with uncertain parameters," Fuzzy Sets and Systems, vol. 130, no. 3, pp. 277-289, 2002.

[25] K. W. Hipel, "Systems engineering approaches for brownfield redevelopment," October 2007, http://researchcommunity.iglooresearch.org/systemseng.

[26] United States Environmetnal Protection Agency (USEPA), "Characteristics of sustainable brownfields projects," Tech. Rep. EPA500-R-98-001G, USEPA, Washington, DC, USA, 1998.

[27] K. W. Hipel, M. M. Jamshidi, J. M. Tien, and C. C. White III, "The future of systems, man, and cybernetics: application domains and research methods," IEEE Transactions on Systems, Man and Cybernetics, Part C, vol. 37, no. 5, pp. 726-743, 2007.

[28] Q. Wang, K. W. Hipel, and D. M. Kilgour, "Conflict analysis in brownfield redevelopment: the erase program in Hamilton, Ontario," in Proceedings of the IEEE International Conference on Systems, Man, and Cybernetics (SMC'08), Singapore, October 2008.

[29] D. El-Gamal, Streamlined approach to vadose zone modeling: a contribution to brownfield redevelopment, Ph.D. dissertation, Department of Civil and Environmental Engineering at Wayne State University, Detroit, Mich, USA, 2005.

[30] D. G. Luenberger, "A correlation pricing formula," Journal of Economic Dynamics E Control, vol. 26, no. 7-8, pp. 1113-1126, 2002.

[31] C. A. De Sousa, The brownfield problem in urban canada: issues, approaches, and solutions, Doctoral dissertation, University of Toronto, Toronto, Canada, 2000.

[32] City of Hamilton, "Hamilton ERASE (Environmental Remediation and Site Enhancement) Community Improvement Plan," Report, 2005.

[33] I. Erzi-Akcelik, An analysis of uncertainty in brownfield redevelopment using real options, Ph.D. dissertation, Department of Civil and Environmental Engineering, Carnegie Mellon University, Pittsburgh, Pa, USA, May 2002.

[34] Frontline Environmental Management Inc., "Restoration work plan for the ralgreen community," Internal Report 148-05, Frontline, Baltimore, Md, USA, November 2001.

[35] Project Management Institute, A Guide to the Project Management Body of Knowledge, Project Management Institute, Newton Square, Pa, USA, 2004.

[36] B. Liu, Uncertainty Theory, Springer, Berlin, Germany, 2nd edition, 2007. 


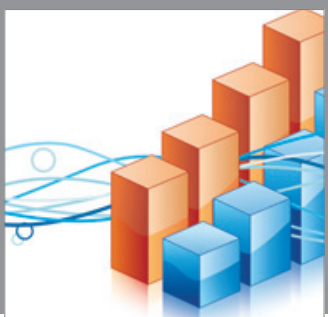

Advances in

Operations Research

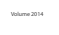

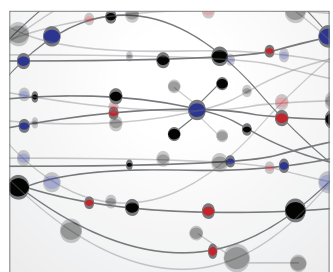

\section{The Scientific} World Journal
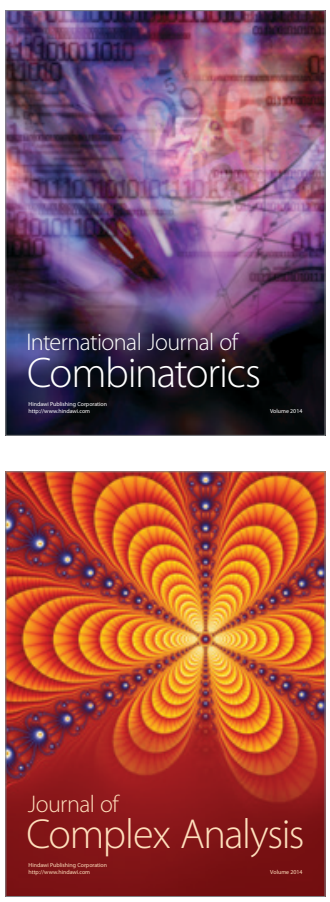

International Journal of

Mathematics and

Mathematical

Sciences
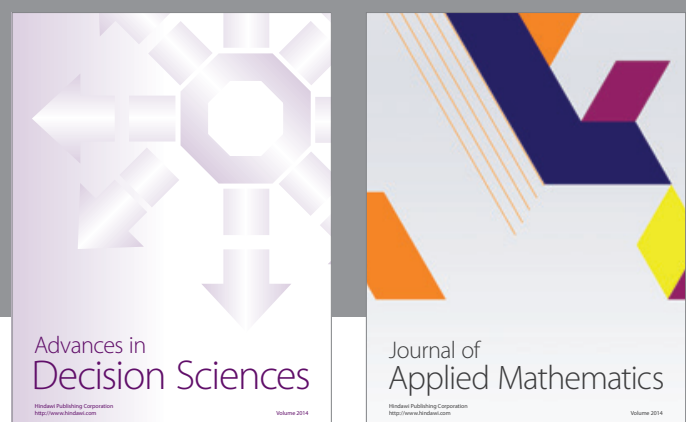

Journal of

Applied Mathematics
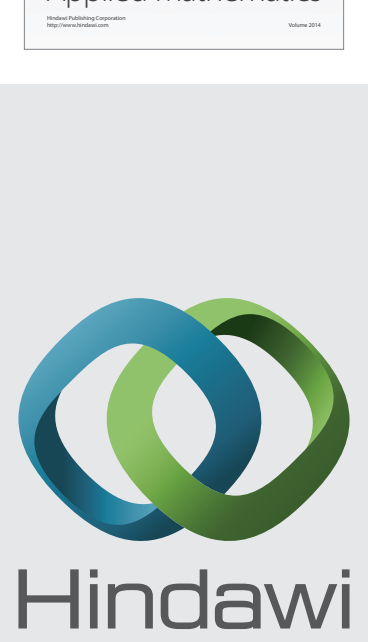

Submit your manuscripts at http://www.hindawi.com
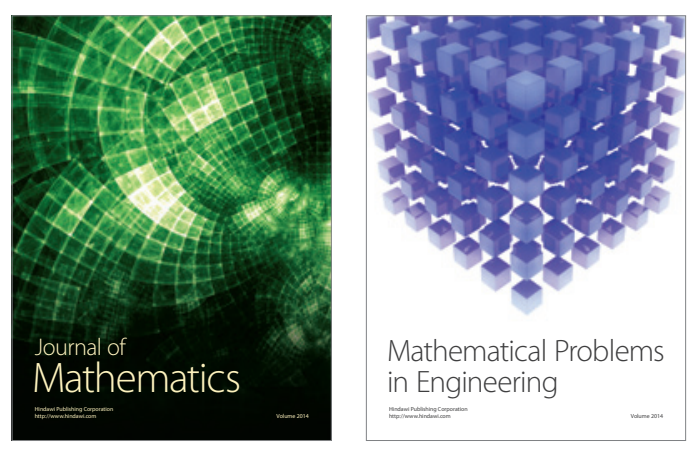

Mathematical Problems in Engineering
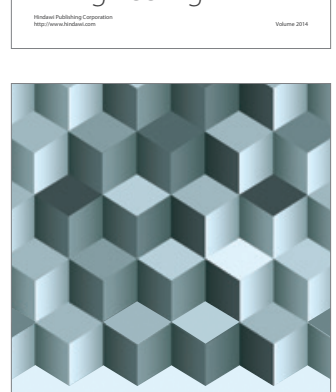

Journal of

Function Spaces
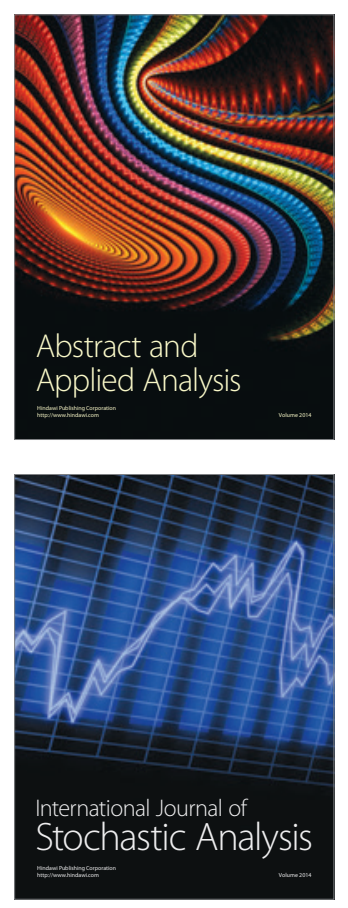

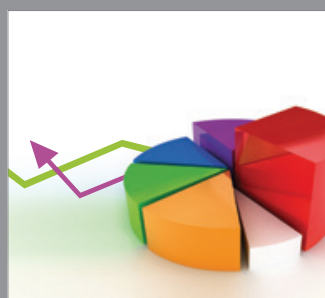

ournal of

Probability and Statistics

Promensencen
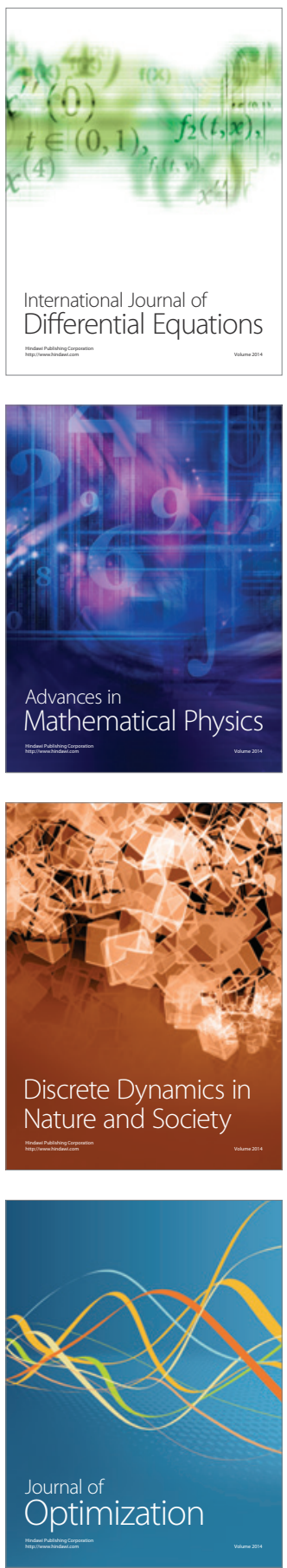